This item was submitted to Loughborough's Research Repository by the author.

Items in Figshare are protected by copyright, with all rights reserved, unless otherwise indicated.

\title{
Thirst responses following high intensity intermittent exercise when access to ad libitum water intake was permitted, not permitted or delayed
}

PLEASE CITE THE PUBLISHED VERSION

http://dx.doi.org/10.1016/j.physbeh.2016.01.016

\section{PUBLISHER}

(C) Elsevier

VERSION

AM (Accepted Manuscript)

\section{PUBLISHER STATEMENT}

This work is made available according to the conditions of the Creative Commons Attribution-NonCommercialNoDerivatives 4.0 International (CC BY-NC-ND 4.0) licence. Full details of this licence are available at: https://creativecommons.org/licenses/by-nc-nd/4.0/

\section{LICENCE}

CC BY-NC-ND 4.0

\section{REPOSITORY RECORD}

Mears, Stephen A., Phillip Watson, and Susan M. Shirreffs. 2019. "Thirst Responses Following High Intensity Intermittent Exercise When Access to Ad Libitum Water Intake Was Permitted, Not Permitted or Delayed". figshare. https://hdl.handle.net/2134/20187. 
1 Title

2 Thirst responses following high intensity intermittent exercise when access to ad libitum

3 water intake was permitted, not permitted or delayed

4

5 Author names and affiliations

6 Stephen A Mears ${ }^{\mathrm{a}}$, Phillip Watson ${ }^{\mathrm{a}, \mathrm{b}}$, Susan M Shirreffs ${ }^{\mathrm{a}}$

7 aschool of Sport, Exercise and Health Sciences, Loughborough University, Loughborough,

8 LE11 3TU, United Kingdom

$9 \quad{ }^{\mathrm{b}}$ Department of Human Physiology, Vrije Universiteit Brussel, Brussels B-1050, Belgium. 10

11 Corresponding Author:

12 Stephen A Mears

13 School of Sport, Exercise and Health Sciences,

14 Loughborough University,

15 Loughborough,

16 LE11 3TU,

17 United Kingdom

18 Telephone: 01509226352

19 Fax: 01509226301

20 Email: S.A.Mears@lboro.ac.uk

21

22 Present address

23 PW: Department of Human Physiology, Vrije Universiteit Brussel, Brussels B-1050, 24 Belgium. 
Abstract

An increase in subjective feelings of thirst and ad libitum drinking caused by an increase in serum osmolality have been observed following high intensity intermittent exercise (HIIE) compared to continuous exercise. The increase in serum osmolality is closely linked to the rise in blood lactate and serum sodium concentrations. However, during an ensuing recovery period after HIIE when serum osmolality will decrease, the resultant effect on sensations of thirst and subsequent water intake is unclear. Therefore the aim of the study was to assess the sensations of thirst and subsequent effect on ad libitum water consumption when water intake was immediately allowed, delayed or prevented following a period of HIIE.

Methods Twelve males (26 \pm 4 years, $80.1 \pm 9.3 \mathrm{~kg}, 1.81 \pm 0.05 \mathrm{~m}, \dot{\mathrm{VO}}_{\text {2peak }} 60.1 \pm 8.9 \mathrm{ml} . \mathrm{kg}^{-}$ ${ }^{1} . \mathrm{min}^{-1}$ ) participated in three randomised trials undertaken $7-14$ days apart. Participants rested for 30 min then completed a 60 min HIIE exercise period (20 x 1 min at $100 \% \dot{\mathrm{VO}}_{2 \text { peak }}$ with 2 min rest) followed by 60 min of recovery, during which ad libitum water intake was provided immediately (W), delayed until the final 30 min (W30) or not permitted (NW). Body mass was measured at the start and end of the trial. Blood lactate and serum sodium concentrations serum osmolality and sensation of thirst were measured at baseline, immediately post-exercise and during the recovery.

Results Body mass loss was different between all trials (W: $0.25 \pm 0.45$, W30: $0.49 \pm 0.37$, NW: $1.29 \pm 0.37 \% ; \mathrm{p}<0.05)$. Sensations of thirst peaked post-exercise and decreased in $\mathrm{W}$ and W30 following water ingestion $(\mathrm{p}<0.05)$. Total voluntary water intake was greater in $\mathrm{W}$ trial $(0.846 \pm 0.417 \mathrm{v} 0.630 \pm 0.277 \mathrm{l} ; \mathrm{p}<0.05)$ but was similar during the first $30 \mathrm{~min}$ period of allowed drinking ( $0.618 \pm 0.297$ vs. $0.630 \pm 0.277$ l; p>0.05). Serum osmolality (299 \pm 6 v $298 \pm 5$ vs. $298 \pm 3$ mOsmol.kg-1), blood lactate (7.1 \pm 1.1 vs. $7.2 \pm 1.1$ v $7.1 \pm 1.2$ mmol.l' $\left.{ }^{1}\right)$ and serum sodium concentrations (142 \pm 2 vs. $145 \pm 2$ v $145 \pm 2$ mmol. ${ }^{-1}$ ) peaked postexercise (W vs. W30 vs. NW; $\mathrm{p}<0.05)$ but were not different between trials $(\mathrm{p}>0.05)$.

Conclusions Sensations of thirst were increased following HIIE and remained until satiated by water intake. This was despite the likely primary stimulus, serum osmolality, decreasing during the recovery period following a post-exercise peak. A combined effect of reduction in blood lactate and serum sodium concentrations, restoration of plasma volume and water intake contributed to the similar decrease in serum osmolality observed throughout the trials. 
58 Highlights

59

- HIIE caused an increase in blood lactate concentrations, raising serum osmolality

60

- Despite decreased serum osmolality during recovery, thirst remained until satiated

61

- Delaying drinking 30min resulted in a similar volume consumed immediately post

62 HIIE

63

64 Key words:

65 Blood lactate; serum osmolality; thirst; water intake; satiation

66 
Thirst is an innate behaviour that drives an episodic desire to drink and is normally an adequate stimulus to maintain a state of euhydration under resting conditions [1]. However, when the body is placed under physiological stress, the thirst response often results in sufficient water consumed to satiate sensations of thirst but not to completely replace fluid losses (involuntary dehydration). Stricker and Verbalis [2] proposed two mechanisms relating to the generation of thirst sensations and desire to drink: hyperosmolality and hypovolaemia, whilst sensations of dry mouth have also been proposed as a mechanism of thirst $[3,4,5]$.

In relation to hyperosmolality, serum osmolality thresholds at rest have been identified that drive arginine vasopressin (AVP) release (approximately $285 \mathrm{mOsmol} . \mathrm{kg}^{-1}$; [6]) and sensations of thirst (approximately 290mOsmol. $\mathrm{kg}^{-1}$; [7]), whilst it has also been suggested that changes in serum osmolality of approximately $5 \mathrm{mOsmol} . \mathrm{kg}^{-1}$ will stimulate sensations of thirst [8]. Elevations in serum osmolality are detected by osmoreceptors in the organum vasculosum of the lamina terminalis and the subfornical region within the brain. Both of these circumventricular organs lack a blood-brain barrier, therefore allowing hormonal and osmotic stimuli to act [9]. Serum osmolality levels above the threshold for thirst will usually occur due to changes in cell tonicity, but can also arise due to the influence of blood lactate concentrations caused by a period of high intensity intermittent exercise (HIIE) [10]. Hypovolaemia is a common consequence of most exercise intensities, and will primarily occur due to ongoing sweat losses resulting from an effort to maintain body temperature. However, the relatively short duration of HIIE bouts may prevent water losses from reaching a sufficient level to stimulate sensations of thirst (approximately 0.8\% body mass loss; [11]), therefore any change in blood volume following HIIE is likely to arise from changes in blood pressure and subsequent movement of water to the interstitial space [12].

Following HIIE, water moves from the vascular to the interstitial and intracellular spaces $[12,13,14]$. Serum osmolality and subsequent arginine vasopressin release will increase in relation to the increase in blood lactate concentration $[12,14,15,16]$. It has been hypothesised that the negatively charged lactate ions reduce sodium release from the vascular space thus increasing serum sodium concentrations and subsequent osmolality levels [14]. Therefore HIIE may in fact elevate serum osmolality above the threshold for thirst, and consequently influence drinking behaviour independent of associated water losses. 
101 An increase in ad libitum drinking (total volume consumed) has been observed following a 102 period of HIIE compared to continuous exercise [10]. The observed increase in water intake 103 was associated with an increase in blood lactate, serum sodium and vasopressin 104 concentrations, an increase in serum osmolality and a tendency for greater subjective feelings

105 of thirst. During the recovery period access to water intake was allowed immediately after 106 exercise. It was therefore difficult to determine if thirst and subsequent drinking behaviour 107 was influenced by the reduction of factors that stimulated sensations of thirst (i.e. serum 108 osmolality and associated variables), the satiation of thirst sensations or a combination. 109 Although not measured, it was also possible that the increased respiration rate during the 110 HIIE may have contributed to the increases in mouth dryness and thirst observed by Mears \& 111 Shirreffs [10]. By delaying and also preventing access to ad libitum water intake it is 112 possible the mechanisms relating to thirst and serum osmolality can be better understood and 113 a clearer insight into role played by HIIE on drinking behaviour can be established.

115 The aim of the study was to assess the sensations of thirst and the subsequent effect on $a d$ 116 libitum water intake during a recovery period following HIIE, when access to water was 117 allowed immediately, delayed or prevented. It was hypothesised that sensations of thirst 118 would increase, due to an increase in serum osmolality and that this would drive drinking 119 behaviours. Delaying or preventing drinking would not satiate sensations of thirst. 


\subsection{Participants}

123 Twelve healthy male participants (age $26 \pm 4$ years, mass $80.1 \pm 9.3 \mathrm{~kg}$, height $1.81 \pm 0.05$ $\mathrm{m}, \dot{\mathrm{VO}_{2 p e a k}} 60.1 \pm 8.9 \mathrm{ml} \cdot \mathrm{kg}^{-1} \cdot \mathrm{min}^{-1}$ ) took part in three experimental trials, in a randomised order. The experimental protocol was explained to all participants verbally and in writing and written informed consent was provided. The experiment was approved by the Loughborough University Ethical Advisory Committee.

\subsection{Experimental protocol}

130 Participants visited the laboratory on five separate occasions for a peak oxygen uptake ( $\dot{\mathrm{V}}$ $131 \mathrm{O}_{2 \text { peak) }}$ test, a familiarisation trial and three experimental trials differing in the time period 132 during which ad libitum water intake was allowed following exercise; water permitted throughout the entire recovery period (W), water delayed until 30 minutes after exercise until the end of the recovery period (W30) and no water permitted at all during the recovery period (NW).

The first visit involved a discontinuous incremental test to volitional fatigue undertaken on an electrically braked cycle ergometer (Lode Corival; Lode BV, Groningen, Netherlands) was used to determine peak power and $\dot{\mathrm{V}}{ }_{2 \text { peak. }}$ Expired gas was collected for $1 \mathrm{~min}$ at the end of each four minute stage. The familiarisation trial was identical to the $\mathrm{W}$ trial, and intended to inform the participants of the experimental procedures employed throughout the study. Participants were asked to record their dietary intake in the 24 hours prior to the first experimental trial (food and drink consumed, amount and method of preparation) and refrain

144 from strenuous physical activity and consumption of alcohol. For each subsequent trial they were asked to repeat this. Participants were asked to arrive at the laboratory after an overnight fast with the exception of consumption of $500 \mathrm{ml}$ of water ingested two hours before arrival at the laboratory to ensure they were in a euhydrated state.

149 Experimental trials began in the morning at the same time for each participant and were separated by a period of 7-14 days. A schematic outline of the trial is shown in Figure 1. Experimental trial order was randomised and participants were not aware of which trial they 


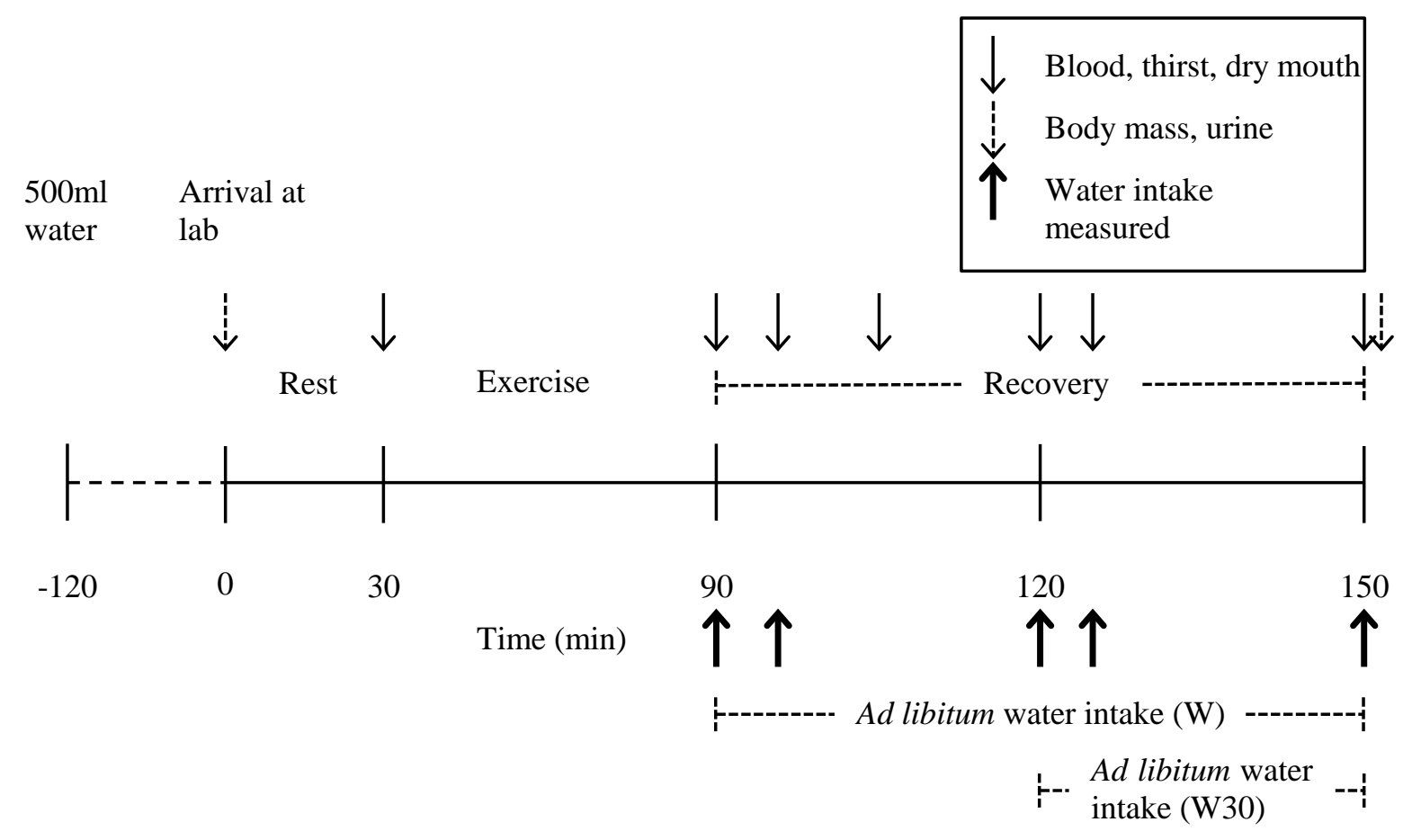

Figure 1. Schematic diagram indicating the testing protocol. Arrows represent sampling points.

153 were participating in when arriving at the laboratory for the first and second experimental 154 trials.

155

156 On arrival at the laboratory, participants voided and asked to empty their bladder; total urine 157 volume was measured and a $5 \mathrm{ml}$ aliquot retained for analysis. Nude body mass was measured. Participants were asked to insert a rectal thermistor $10 \mathrm{~cm}$ past the anal sphincter, and a heart rate monitor (Polar Vantage; Kempele, Finland) was positioned. Throughout the trials, core $\left(\mathrm{T}_{\mathrm{c}}\right)$ and skin $\left(\mathrm{T}_{\mathrm{sk}}\right)$ temperature were measured continuously, and data were averaged every 10 min (BIOPAC MP100 System; BIOPAC, Santa Barbara, CA, USA).

162 Mean weighted skin temperature was calculated using the formula outlined by Ramanathan

163 [17]. Participants rested in a seated position for 30 minutes in a comfortable environment $164\left(22.3 \pm 0.4^{\circ} \mathrm{C}\right.$ and $47 \pm 9 \%$ relative humidity; $\left.\mathrm{RH}\right)$. Every 10 minutes during rest, exercise and recovery heart rate was recorded. Following the 30 minutes seated rest, participants completed two $100 \mathrm{~mm}$ visual analogue subjective feeling questionnaires relating to symptoms of thirst and dry mouth $(0 \mathrm{~mm}=$ not at all thirsty/mouth not at all dry, $100 \mathrm{~mm}=$ very thirsty/mouth very dry). During the baseline period a $21 \mathrm{~g}$ cannula (Surflo, Terumo,

169 Leuven, Belgium) was inserted into a superficial vein on the forearm to allow venous blood sampling. At the end of the rest period a baseline blood sample $(7.5 \mathrm{ml})$ was collected. 
172 Participants then completed 60 minutes of HIIE, comprising of repeated cycles of 1 min of

173 cycle exercise at a power output equal to the maximum power achieved during the $\dot{\mathrm{VO}}_{2 \text { peak }}$ 174 test, followed by 2 min rest. This was undertaken in $23.0 \pm 0.4^{\circ} \mathrm{C}$ and $48 \pm 10 \% \mathrm{RH}$. During 175 the 60 minute period this pattern of activity was repeated 20 times. A blood sample (7.5 ml) 176 was collected immediately following the completion of exercise and the two subjective 177 feelings questionnaire were repeated. Participants were then seated at rest for 60 minutes in $178 \quad 22.7 \pm 0.3^{\circ} \mathrm{C}$ and $47 \pm 10 \% \mathrm{RH}$.

In the $\mathrm{W}$ trial ad libitum water intake $\left(10 \pm 3^{\circ} \mathrm{C}\right)$ was allowed for the whole duration of the recovery period, with the volume of water ingested recorded between 0-5 minutes, 5-30 minutes, 30-35 minutes and 35-60 minutes. In the W30 trial, ad libitum water intake was delayed until 30 minutes of the recovery period had passed. Water intake was then measured between 30-35 minutes and 35-60 minutes. In the NW trial no water was permitted during the 60 min recovery period. The participant was not made aware of the volume consumed, or that the volume was being measured. Participants were informed at the start that they could drink as they wanted, that the bottle would be refilled if necessary and were provided with no external cues to drink. Blood samples were collected at 5, 15, 30, 35 and 60 minutes and thirst and dry mouth subjective feelings questionnaires were completed. At the end of the recovery period following the final blood sample, participants voided, the urine volume was measured and a $5 \mathrm{ml}$ sample was retained for later analysis. Nude body mass was then measured, after which, participants were allowed to leave the laboratory. Ambient temperature and relative humidity was measured at 10 minute intervals (RH85 Digital Thermo-Hygrometer; Omega, Manchester, UK).

195

\subsection{Sample analysis}

197 For each $7.5 \mathrm{ml}$ venous blood sample, a $1.0 \mathrm{ml}$ aliquot was mixed with an anticoagulant $\left(\mathrm{K}^{+}\right.$ 198 EDTA; $1.5 \mathrm{mg}^{-1}$ ) for analysis of haemoglobin concentration (Cyanmethaemoglobin 199 method; Sigma, St Louis, MO, USA), haematocrit (micro-centrifugation; Hawksley, 200 Worthing, UK) and glucose concentration. A further $5.0 \mathrm{ml}$ was mixed with anticoagulant $201\left(\mathrm{~K}^{+}\right.$EDTA; $\left.1.5 \mathrm{mg} \cdot \mathrm{ml}^{-1}\right)$ and from this, plasma was separated and frozen at $-80^{\circ} \mathrm{C}$ for later 202 analysis of hormone concentrations. The remaining blood $(\sim 2.0 \mathrm{ml})$ was allowed to clot at 203 room temperature before being centrifuged at $3000 \mathrm{rpm}$ for $15 \mathrm{~min}$ at $4^{\circ} \mathrm{C}$ to yield serum. 
204 This was later analysed for sodium concentration by flame photometry (Corning Clinical

205 Flame Photometer 410C; Corning Ltd., Halstead, Essex, UK) and osmolality by freezing 206 point depression (Gonotec Osmomat auto Cryoscopic Osmometer; Gonotec, Berlin, 207 Germany). Blood and plasma volume changes were calculated from haemoglobin 208 concentrations and haematocrit values using the method of Dill and Costill [18]. 209 Anticoagulated blood $(100 \mu \mathrm{l})$ was added to $0.3 \mathrm{M}$ perchloric acid in a ratio of 1:10 in 210 duplicate for analysis of glucose by the GOD-PAP method (Randox Laboratories Ltd., 211 Crumbin, UK) and lactate by fluorimetry using the method outlined by Maughan [19]. 212 Enzyme immunoassay (Enzyme Immunoassay; Enzo Life Sciences, Ann Arbor, MI, USA) 213 was used to measure plasma arginine vasopressin and aldosterone concentrations using $100 \mu \mathrm{l}$ 214 samples. Samples were measured in duplicate.

216 The volume of each urine void was measured and a $5 \mathrm{ml}$ sample retained and analysed for 217 osmolality by freezing point depression (Gonotec Osmomat auto Cryoscopic Osmometer; 218 Gonotec, Berlin, Germany).

219

\subsection{Statistical analysis}

221 Data were checked for normality of distribution using Shapiro-Wilks tests. Normally distributed data with one factor (overall fluid balance variables) were analysed using a oneway ANOVA and data with two factors (time dependent fluid balance variables, blood variables, thirst and mouth dryness, temperatures, heart rate and RPE) were analysed using a two-way repeated measures ANOVA design. If a significant ANOVA result was found, to identify where the statistical differences occurred, paired samples t-tests with Bonferroni correction were performed. Using Friedman's ANOVA and Wilcoxon signed-rank tests nonparametric data was examined (aldosterone concentration). On non-parametric data post-hoc tests were performed when significant and non-significant interaction effects were found. Linear regression values and Pearson's product moment correlation coefficients and Spearmon's ranked correlation coefficients were calculated when appropriate. Correlation analysis was performed between variables that were deemed to be related in terms of water balance and the mechanism identified by Nose et al. [14] (serum osmolality/ serum sodium/ blood lactate). Statistical significance was accepted when $\mathrm{p}<0.05$. When post-hoc tests were conducted, p values presented were multiplied to correct for repeated samples. Data is expressed as mean \pm SD except for aldosterone concentration, which is median (range). Error bars plotted above time points represent a group standard deviation of all samples in all 
238 trials at that time point. This was to improve clarity of the figures and reduce potential 239 confusion of overlapping error bars. Statistical analysis was conducted using Statistical 240 Package for the Social Sciences for Windows, version 18.0 (SPSS inc, Chicago, IL, USA). 


\subsection{Baseline measures}

244 There was no difference in body mass measured at baseline between trials (Table 1; $>>0.05$ ).

245 Similar results between trials for serum osmolality (284 \pm 3 vs. $284 \pm 3$ v $285 \pm 3$ 246 mOsmol. $\mathrm{kg}^{-1}$ for W, W30 and NW respectively) and urine osmolality (409 \pm 221 vs. $434 \pm$ 247256 vs. $454 \pm 238$ mOsmol. $\mathrm{kg}^{-1}$ for W, W30 and NW respectively; p>0.05) suggests that 248 participants arrived in a similar state of hydration, interpreted as euhydrated [20, 21].

249

250

3.2 Subjective feelings questionnaires (thirst and mouth dryness)

251 Peak sensations of thirst were reported in all trials immediately post-exercise compared to 252 baseline $(\mathrm{p}<0.05$; Figure 2a), with no differences apparent between trials $(\mathrm{p}>0.05)$. 253 Following the onset of water intake when ad libitum fluid was available, thirst sensations 254 decreased $(\mathrm{p}<0.05)$. Baseline and peak values of sensations of mouth dryness reported at post-exercise were similar between all trials ( $>0.05$; Figure $2 b$ ). In the $\mathrm{W}$ and $\mathrm{W} 30$ trials, sensations of mouth dryness decreased following consumption of water. Thirst and mouth dryness were strongly positively correlated in all three trials $(\mathrm{p}<0.001$; Table 2$)$.
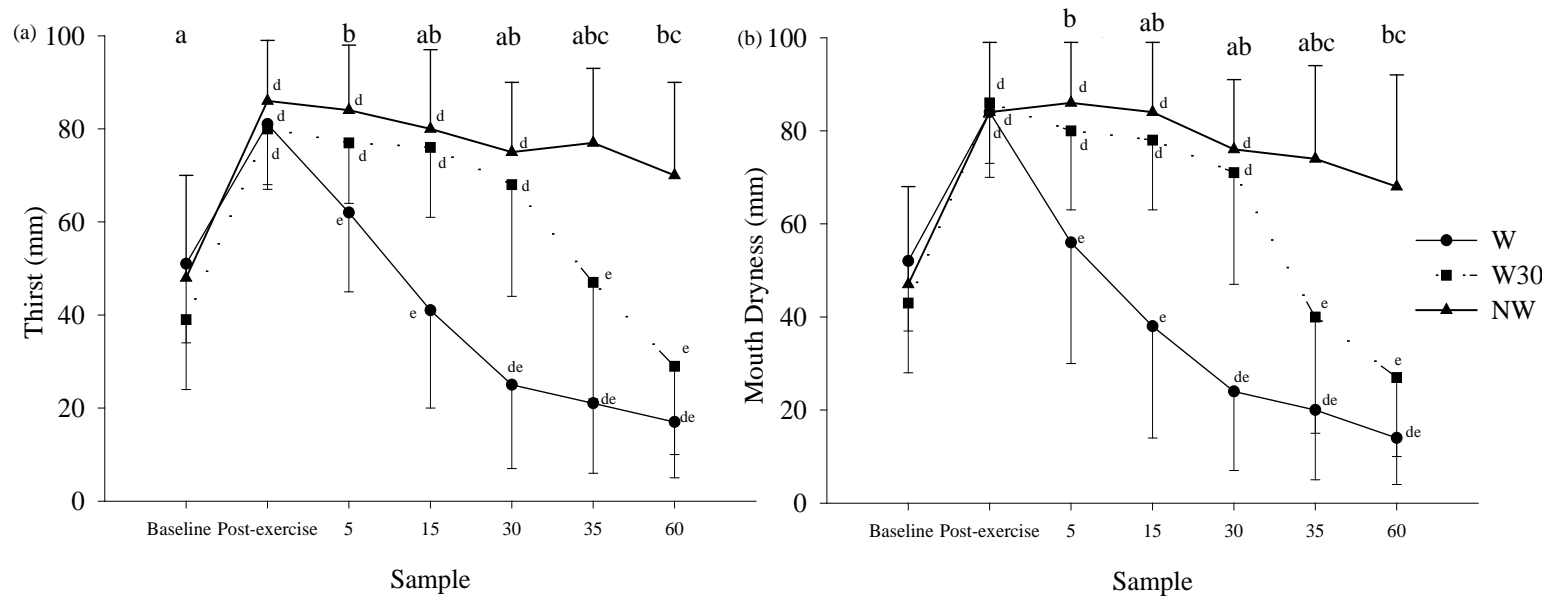

Figure 2. Subjective feeling questionnaire responses for (a) thirst and (b) mouth dryness over the duration of each trial. ${ }^{\text {a }}$ denotes difference between $\mathrm{W}$ and $\mathrm{W} 30$ trials, ${ }^{\mathrm{b}}$ denotes difference between $\mathrm{W}$ and NW trials, ${ }^{c}$ denotes difference between W30 and NW trials, ${ }^{\mathrm{d}}$ denotes difference within the trial compared to baseline and ${ }^{\mathrm{e}}$ denotes difference within the trial compared to post-exercise $(\mathrm{p}<0.05)$. 


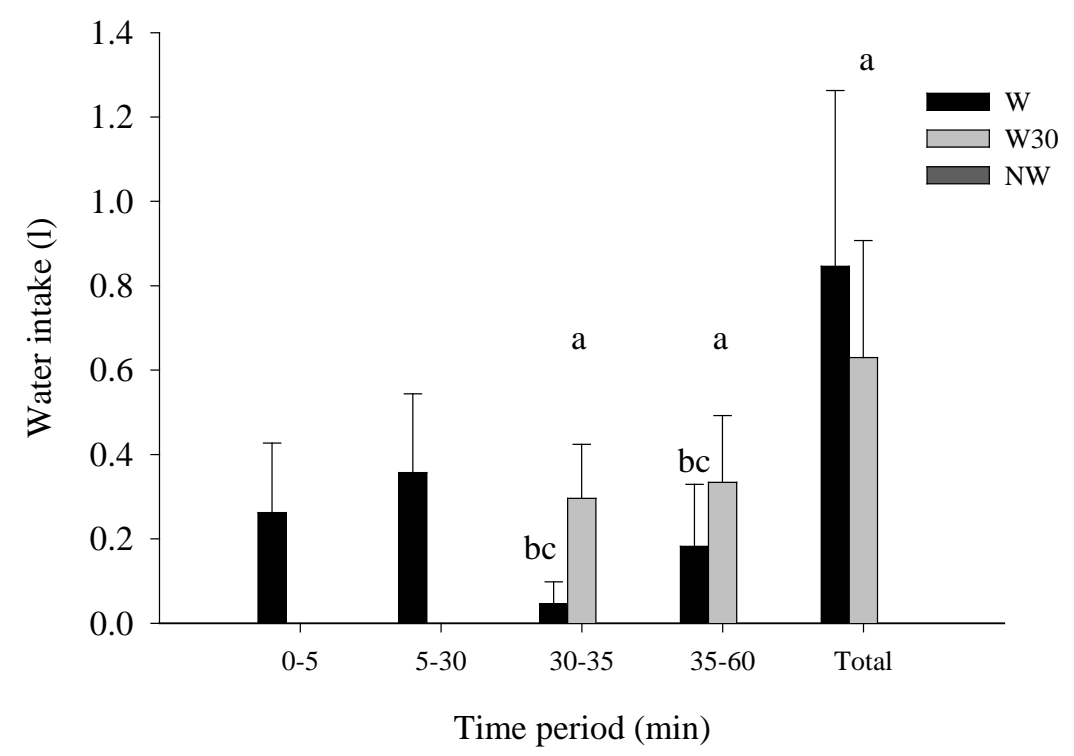

Figure 3. Water intake (l) during each trial. Comparison between W and W30 trials. ${ }^{a}$ denotes difference between trials, ${ }^{b}$ denotes difference to 0-5 $\min (\mathrm{W})$ and ${ }^{\mathrm{c}}$ denotes different to 5-30 $\min (\mathrm{W})(\mathrm{p}<0.05)$.

3.3 Body water balance

261 Body mass decreased from the start to the end of the trial in the W30 and NW trial $(\mathrm{p}<0.05)$,

262 whilst percentage decrease in body mass was greater in the NW trial compared to the W and 263 W30 trials $(\mathrm{p}<0.05$; Table 1). Sweat losses and post-exercise urine output were similar 264 between trials ( $>>0.05$; Table 1 ). Total water intake was greater in the $\mathrm{W}$ trial compared to 265 the W30 trial ( $p=0.009$; Figure 3) with similarities observed between volumes consumed 266 when initial drinking periods were compared $(\mathrm{p}>0.05)$. The proportion of water lost through 267 sweating that was subsequently replaced tended to be greater in the $\mathrm{W}$ trial compared to the 268 W30 trial $(p=0.08)$. Four participants ingested sufficient water during the recovery period to replace more than $100 \%$ of water lost in the $\mathrm{W}$ trial.

\subsection{Blood analysis}

273 No difference in serum osmolality was observed between trials at all sample points ( $>0.05$;

274 Figure 4a). Peak osmolality values occurred immediately post-exercise, before decreasing 275 during the recovery period $(\mathrm{p}<0.05)$. Similar to serum osmolality, blood lactate (Figure $4 \mathrm{~b})$ and serum sodium concentrations (Figure 4c) were similar between trials ( $\mathrm{p}>0.05$ ) with peak concentrations occurring immediately post-exercise $(\mathrm{p}<0.05)$. Blood lactate concentrations 


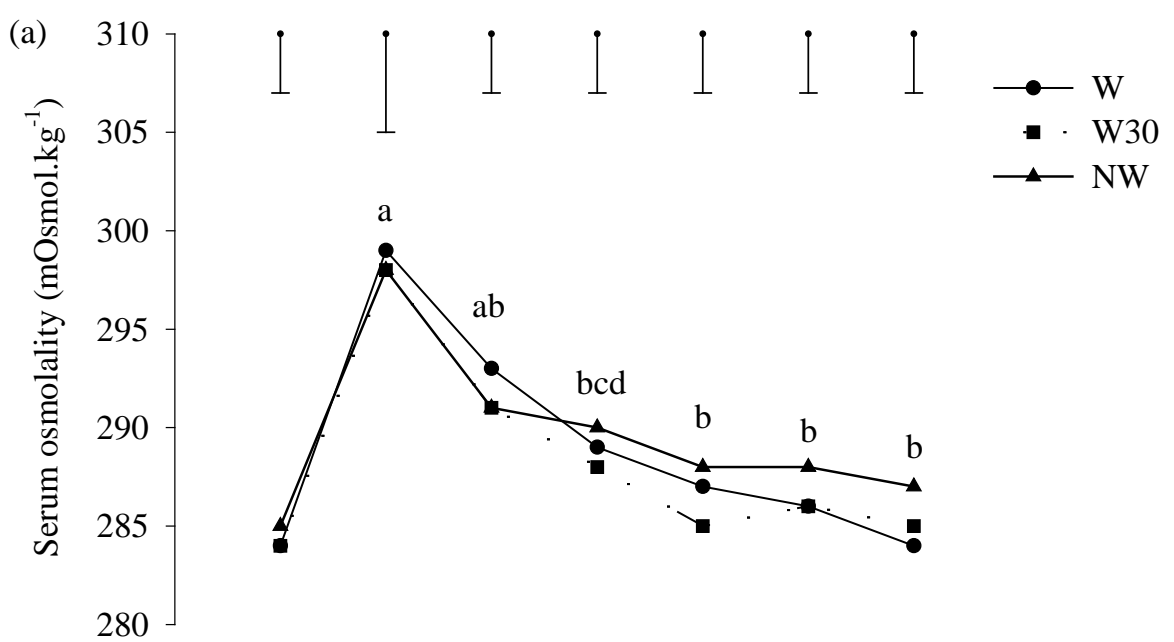

(b)

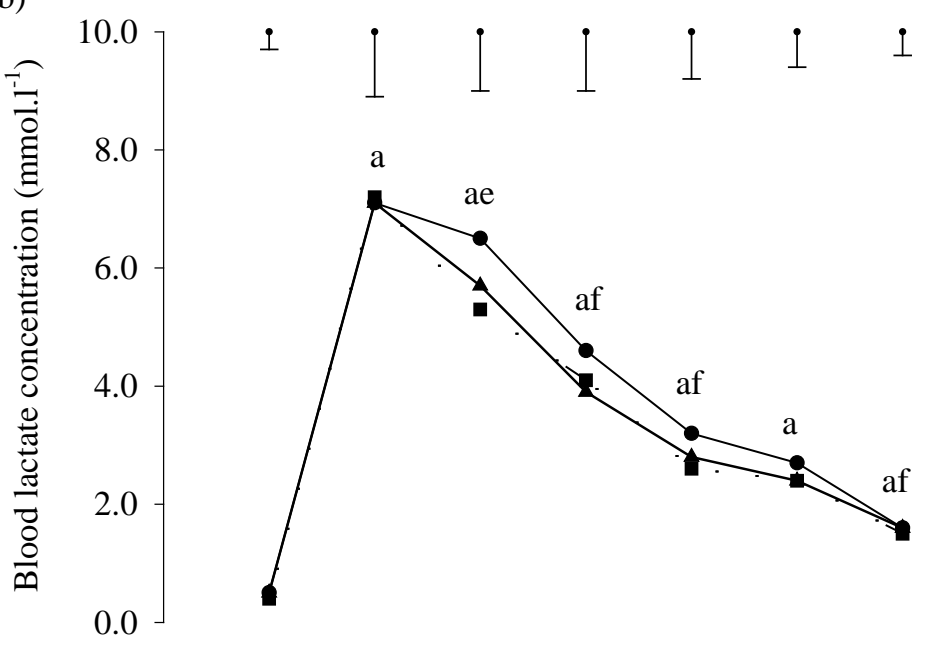

(c)

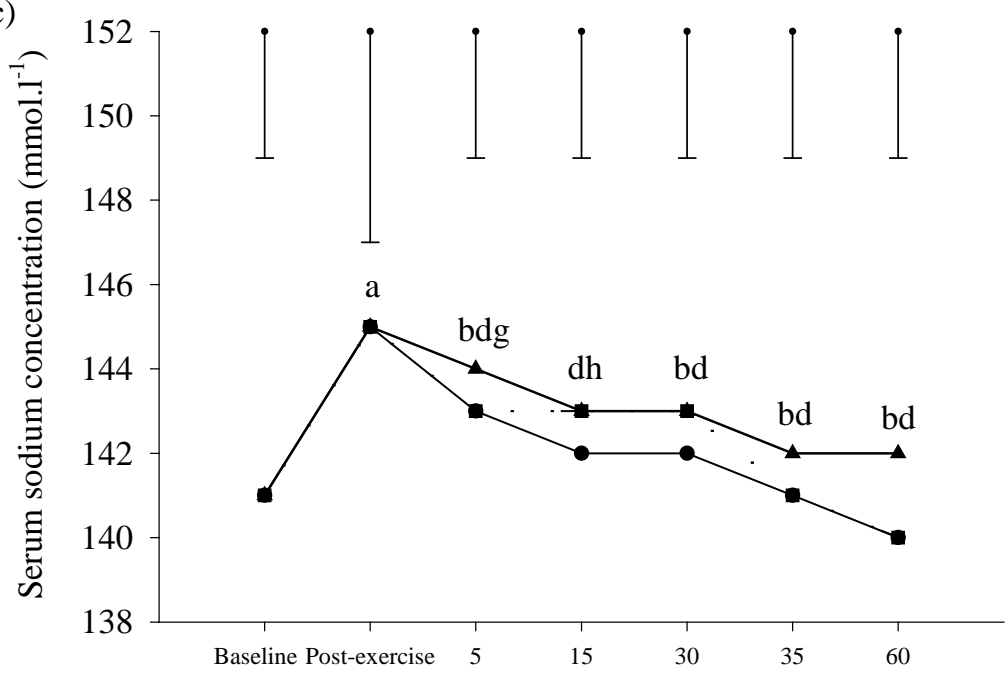

Samnle

Figure 4. (a) Serum osmolality, (b) blood lactate concentration and (c) serum sodium concentration over the duration of each trial. Error bars plotted above time points represent the standard deviation of all samples in all trials at that time point. ${ }^{a}$ denotes different to baseline in all trials, ${ }^{b}$ denotes different to post-exercise in all trials, ${ }^{c}$ denotes different to baseline in $\mathrm{W}$ trial, ${ }^{\mathrm{d}}$ denotes different to baseline in $\mathrm{NW}$ trial, ${ }^{\mathrm{g}}$ denotes different to baseline in W30 trial, ${ }^{e}$ denotes different to previous sample in W30 and NW trials, ${ }^{\mathrm{f}}$ denotes different to previous sample in all trials, ${ }^{\mathrm{h}}$ denotes different to post-exercise sample in $\mathrm{W}$ and $\mathrm{NW}$ trial $(\mathrm{p}<0.05)$. 
concentrations in the NW trial remained elevated above baseline throughout the recovery period, whilst in the in the $\mathrm{W}$ and $\mathrm{W} 30$ trials, serum sodium concentrations returned to baseline after 5 and 15 minutes respectively. AVP concentrations were similar between trials ( $>0.05$; Figure 5a) with peak concentrations found post-exercise $(\mathrm{p}<0.05)$. During the W30, the onset of water intake did not appear to cause further changes in any of the blood variables measured ( $\mathrm{p}>0.05)$.
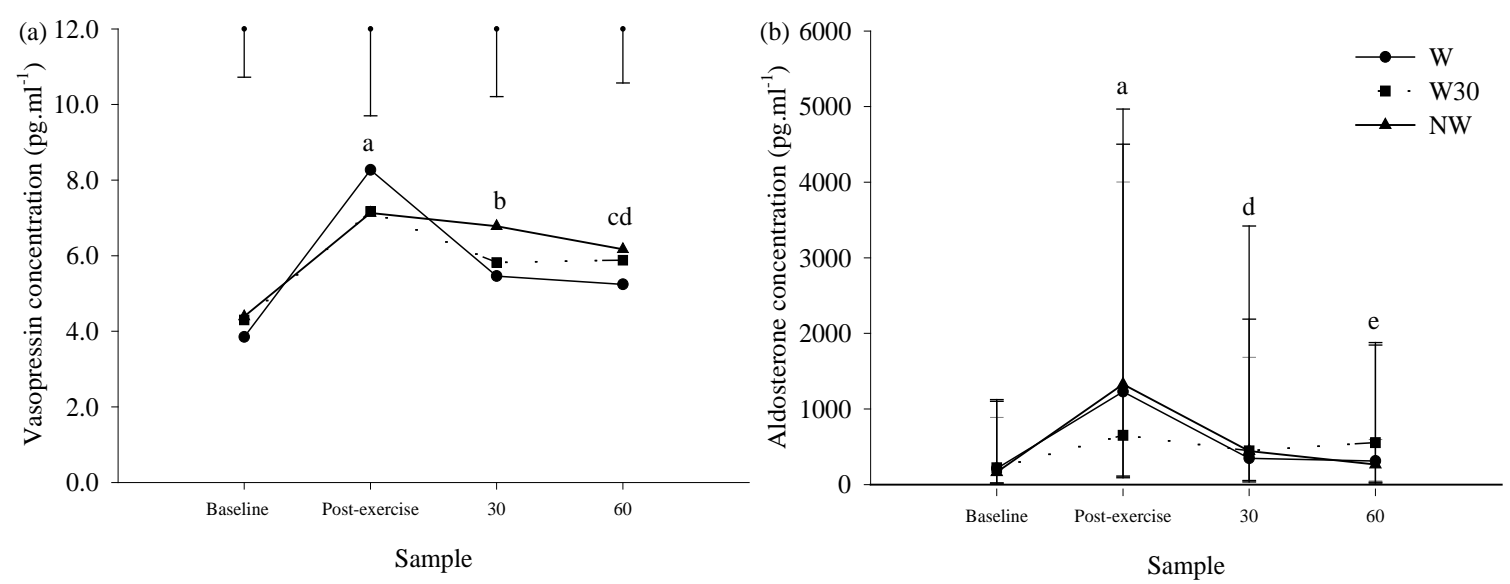

Figure 5. (a) Vasopressin (mean \pm SD) and (b) aldosterone (median (range)) concentrations over the duration of each trial. Error bars plotted above time points represent the standard deviation of all samples in all trials at that time point. ${ }^{a}$ denotes different to baseline values in all trials, ${ }^{\mathrm{b}}$ denotes different to baseline in $\mathrm{W},{ }^{c}$ denotes different to post-exercise in $\mathrm{W},{ }^{\mathrm{d}}$ denotes different to baseline in $\mathrm{W}$ and $\mathrm{W} 30$, denotes different to post-exercise in all trials $(\mathrm{p}<0.05)$.

Thirst sensations were positively correlated to serum osmolality, serum sodium and blood lactate concentrations in all three trials $(\mathrm{p}<0.05$; Table 2). Similar responses were observed for sensations of mouth dryness except in the NW trial for serum osmolality. Sensations of thirst and mouth dryness were positively correlated to AVP concentrations in the W and W30 trials $(\mathrm{p}<0.05)$.

Plasma volume changes from baseline were similar between trials at all sample points ( $>>0.05)$ (Figure 6a). In all trials there was a decrease in plasma volume from baseline values at post-exercise and after 5 minutes of the recovery period $(\mathrm{p}<0.05)$ before plasma volume returned to baseline $(\mathrm{p}>0.05)$. Blood volume changes from baseline values were similar between trials at all sample points except at 30 min when there was a decrease in blood volume in the W30 trial compared to an increase in the NW trial (Figure 6b). Decreases from 

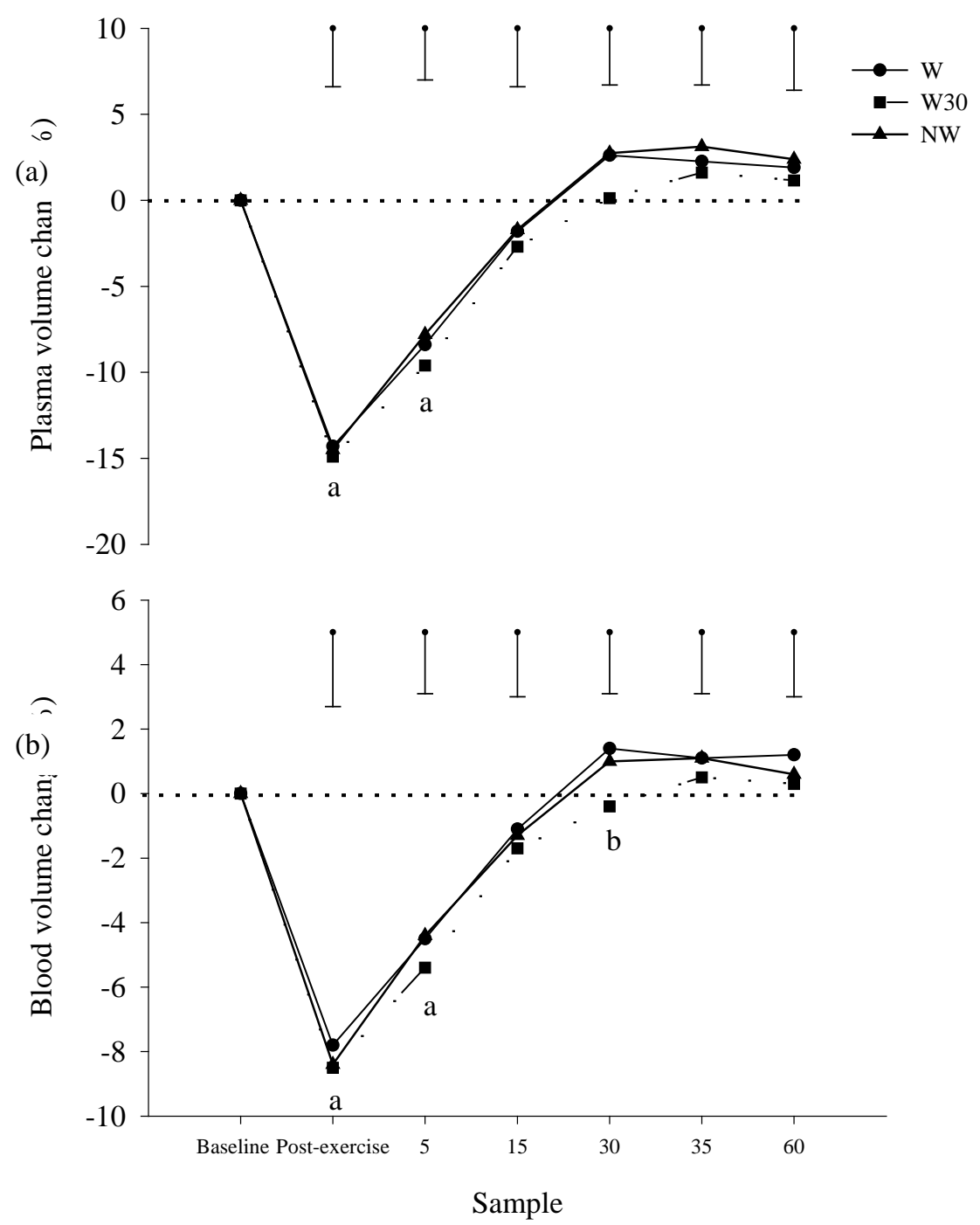

Figure 6. (a) Plasma and (b) blood volume changes compared to baseline values over the duration of each trial. Error bars plotted above time points represent the standard deviation of all samples in all trials at that time point. ${ }^{\text {a }}$ denotes different to baseline values in all trials, ${ }^{\text {b }}$ denotes NW trial different to W30 $(\mathrm{p}<0.05)$.

298 baseline values were observed in all trials at post-exercise and after 5 min of the recovery period $(\mathrm{p}<0.001)$ before blood volumes returned to baseline values. Blood glucose concentrations were similar between trials and sample points (mean concentrations for W: $4.20 \pm 0.30$, W30: $4.20 \pm 0.25, \mathrm{NW}: 4.37 \pm 0.37 \mathrm{mmol}^{-1} \mathrm{I}^{-1}$ p $>0.05$ ).

303 Similar concentrations of aldosterone were found between trials at all sample points ( $\mathrm{p}>0.05$;

304 Figure $5 b)$ with peak values observed post-exercise $(p<0.05)$. Sensations of thirst and mouth dryness were not significantly correlated to aldosterone concentrations ( $\mathrm{p}>0.05)$. 
308 Core temperature increased throughout the HIIE bout in all trials, peaking at the end of the 309 exercise period (W; $38.24 \pm 0.17$, W30: $38.16 \pm 0.36$, NW: $\left.38.04 \pm 0.33^{\circ} \mathrm{C}\right)$. No differences 310 between trials were recorded ( $>0.05$ ). During each trial core temperature was elevated above 311 baseline values after 20 minutes of the exercise period had elapsed and remained elevated 312 above baseline values until 10 minutes into the recovery period in the $\mathrm{W}$ trial and 40 minutes 313 in the W30 and NW trial $(\mathrm{p}<0.05)$. No differences were observed within and between trials 314 for skin temperature measurements $(\mathrm{p}>0.05)$.

315

$316 \quad 3.7$ Heart rate

317 Heart rate was similar between trials at all time points except between the W30 and NW trial 318 after 50 minutes of the recovery period when a higher heart rate was recorded in the NW trial 319 (63 \pm 8 vs. $70 \pm 9$ beats. $\mathrm{min}^{-1} \mathrm{~W} 30$ and NW trials respectively). Peak heart rates were 320 observed during the exercise period of the trials (163 \pm 13 vs. $163 \pm 12$ vs. $162 \pm 13$ 321 beats. $\min ^{-1}$ for $\mathrm{W}, \mathrm{W} 30$ and NW trials respectively) and were elevated from baseline values 322 (61 \pm 10 vs. $57 \pm 8$ vs. $63 \pm 7$ beats. min $^{-1}$ for $\mathrm{W}, \mathrm{W} 30$ and NW trials respectively; $\mathrm{p}<0.05$ ). 
324 The aim of the study was to assess the sensations of thirst and the subsequent effect on ad libitum water intake during a recovery period following HIIE, when access to water was 326 allowed immediately, delayed by $30 \mathrm{~min}$ or prevented. The main finding was that sensations 327 of thirst remained until satiated by voluntary water intake. Despite a delay voluntary water intake was similar between comparable time periods. HIIE increased blood lactate and serum sodium concentrations, therefore increasing serum osmolality providing a large driver for the increases in sensations of thirst.

Sensations of thirst peaked post-exercise in all three trials and remained elevated until immediately after ad libitum water intake was permitted (W and W30 trials). Thirst is a multifactorial sensation that can be caused by a multitude of factors [1, 2], many examined within the context of this study. The main driver appeared to be the increase in serum osmolality as this was significantly raised above suggested thresholds [7]. Sensations of thirst and mouth dryness were also significantly correlated with several other physiological measurements (many interlinking and also contributing to the increase in serum osmolality) including serum sodium and blood lactate concentrations and fluid balance hormones. These factors appeared to contribute to the stimulation of thirst, but despite varying reductions in the measured variables during the recovery period, it was apparent that only through water consumption were sensations of thirst satiated.

Water intake was strongly governed by sensations and the satiation of thirst. Despite the delay in water provision, the volume of water consumed in the $\mathrm{W}$ and $\mathrm{W} 30$ trials to satiate thirst was similar during the first 30 minutes of permitted drinking. In the W30 trial, physiological responses associated with water intake at the onset of drinking (i.e. serum osmolality and plasma vasopressin concentrations) were lower than in the $\mathrm{W}$ trial when drinking was allowed, yet thirst remained elevated. Drinking to alleviate sensations of thirst was strongly correlated with mouth dryness (W: $r=0.959$, W30: $r=0.921$, NW: $r=0.775$ ) and probably suggests that water intake volume was likely driven primarily by oropharyngeal factors. The breakdown of each drinking period providing further indication of this. Consumption of water during the first 5 minutes and the subsequent 25 minute period was comparable in the $\mathrm{W}$ and W30 trials. In studies examining voluntary water intake following a period of dehydration through exercise or water restriction, water intake predominantly occurs at the onset of the drinking period to reduce sensations of mouth dryness and thirst 
commonly detected by osmoreceptors in the oropharyngeal region [3, 4, 22]. Figaro and Mack [4] observed 54\% of total fluid consumed during the initial 5 minute period; largely governed by oropharyngeal stimuli. By infusing fluid directly into the stomach they were able to prevent the satiation of thirst sensations and the reduction in vasopressin concentration. Despite infusion of fluid to return plasma osmolality and plasma volume levels to resting values, when ad libitum fluid intake was permitted, subjects drank to alleviate thirst as detected by dryness of the oropharyngeal region. In the current study there were significant decreases in self-reported sensations of mouth dryness and thirst after ad libitum water intake was allowed. These differences, combined with similar water intake volumes between both 0-5 and 5-30 min in the $\mathrm{W}$ trial and 30-35 and 35-60 min in the W30 trial, would confirm that that the osmoreceptors play an important role in governing voluntary water intake behaviour.

Rather than drinking to replace fluid losses, participants appeared to consume a volume sufficient to relieve the possible unpleasantness and discomfort associated with mouth dryness and thirst. This resulted in a fluid deficit apparent at the end of the recovery period and involuntary dehydration. Voluntary water intake replaced only $82 \pm 39 \%$ and $63 \pm 27 \%$ of the water lost in the $\mathrm{W}$ and $\mathrm{W} 30$ trials respectively, similar to volumes commonly replaced in the literature $[23,24]$. Rapid rehydration is required if body mass losses are large $(>2 \%)$ and/ or there is a need to rehydrate effectively for another bout of exercise within a short period of time [25]. Otherwise a return to a state of euhydration can be achieved gradually through normal meals, snacks and plain water intake. In the current study body mass losses of just over $1 \%$ would not be indicative of a requirement for rapid rehydration.

In addition to mouth dryness sensations of thirst were likely driven by the increase in serum osmolality post-exercise. At rest an increase in serum osmolality above 285 mOsmol.kg ${ }^{-1}$ will stimulate vasopressin release [6], whilst a further increase to above 290 mOsmol.kg-1 will lead to the sensations of thirst [7] and subsequent water intake. In addition a rise in serum osmolality of approximately $5 \mathrm{mOsmol} . \mathrm{kg}^{-1}$ has been deemed sufficient to induce sensations of thirst [8]. However in the model outlined by the authors, a rise in serum osmolality is usually caused by intracellular losses when total body water losses are around $2 \%$ [8]. In the present study, the period of HIIE increased serum osmolality above 290 mOsmol. $\mathrm{kg}^{-1}$ and the increase was greater than $5 \mathrm{mOsmol} . \mathrm{kg}^{-1}$ but body mass losses were approximately $1.3 \%$. The peak in post-exercise serum osmolality caused an increase in vasopressin concentrations and the stimulation of thirst sensation. The rise in vasopressin 
concentration was likely due to osmotically driven signals although it has been shown that

392 high intensity exercise will drive vasopressin release through non-osmotic stimuli [15].

393 Release of vasopressin will increase renal water reabsorption, thereby reducing serum

394 osmolality and as a result, sensations of thirst [2]. However, in the current study, despite an

395 increase in vasopressin and decrease in serum osmolality, sensations of thirst remained until

396 satiated suggesting that key driver in water intake following a delay was behavioural.

397 Correlation analysis indicated that the decrease in serum osmolality following peak values

398 was closely related to the decrease in blood lactate and serum sodium concentrations. It is

399 likely there was also contribution from restoration of plasma volume, and reduction in

400 hydrostatic pressure in the capillary beds [13,26].

401

402 The cause of an increase in serum osmolality following HIIE has been positively related to an

403 increase in blood lactate and serum sodium concentrations alongside haemoconcentration

$404[13,14,26]$. As a key contributor [10], an increase in blood lactate concentrations will

405 prevent serum sodium release into the vascular space, resulting in an increase in osmolality

406 levels [14]. The relative contribution of blood lactate concentrations to the increase in serum

407 osmolality was calculated using the formula assessed by Worthley et al. [27] (Serum 408 osmolality $=2\left[\mathrm{Na}^{+}\right]+[\mathrm{BUN}]+[$ Glucose $]+[$ lactate $\left.]\right)$. The change in osmolality from 409 baseline to post-exercise in the current study of 13-15 mmol. $\mathrm{l}^{-1}$ would have been caused by 410 the increase in serum sodium concentration (contribution of $2 * 4 \mathrm{mOsmol} . \mathrm{kg}^{-1}$ ) and also 411 blood lactate concentration (contribution of 5-7 mOsmol. $\mathrm{kg}^{-1}$ ). It would therefore appear that 412 increased blood lactate concentrations following HIIE contribute both directly and indirectly 413 (through serum sodium concentrations) to the increase in serum osmolality and therefore, the 414 subsequent desire to drink.

415

416 During the recovery period serum osmolality progressively decreased in all three trials. 417 Despite significant decreases from peak values, serum osmolality remained above 418 approximately 290 mOsmol. $\mathrm{kg}^{-1}$ in all three trials until around the 30 minute timepoint 419 suggesting that despite the initial decreases following cessation of exercise serum osmolality 420 was likely still contributing to sensations of thirst. During the recovery period, the longer 421 that thirst remained elevated (i.e. the amount of time that water was withheld), the weaker the 422 correlation between thirst and serum osmolality. This suggests that serum osmolality is a key 423 initial driver of thirst and will still contribute to sensations following a period of HIIE, but 
424 perhaps the relative influence is reduced, particularly when the rise in osmolality is not 425 directly influenced by body water losses.

426

427 The HIIE period was a prolonged period of exercise, involving 20 minutes of exercise over 428 an hour period. Throughout the trials, body mass losses were approximately 1.3\% (based on 429 sweat losses and negating for water intake), enough to stimulate sensations of thirst [11] but 430 often lower than would typically be associated with a sufficient rise in serum osmolality [8]. 431 Although it appears a large contribution to increased serum osmolality and subsequent thirst was caused by increased blood lactate concentrations, it is likely that the hypovolemia experienced would also stimulate sensations of thirst particularly as aldosterone concentrations increased $[2,8]$. To determine this contribution, further work is required to assess the effect of a shorter period of HIIE when body mass losses were minimal.

During a HIIE session, water intake will likely be permitted throughout the exercise period. Thirst is therefore likely to occur throughout a portion of the exercise period resulting in water intake. Although water intake is likely to be small in volume, due to the time available to drink and the inference that water intake is to satiate thirst and reduce mouth dryness, it is possible that volumes similar to the first 5 minutes in the $\mathrm{W}$ trial could be consumed between exercise intervals. Over prolonged periods, this could potentially lead to a gain in body mass and/ or increased frequency of urination [28], which may interfere with exercise. In addition, in many exercise settings, a reduced body mass may be advantageous, particularly in weight bearing sports [29]. Therefore any increase in body mass through water consumption, however slight, may serve to increase the metabolic cost of exercise.

As shown in the study, thirst is a multi-factorial sensation arising from numerous stimuli; however it is possible that factors such as stomach distension may have influenced sensations of thirst and subsequent water intake [30]. Unfortunately this was not measured in the current study; this may have improved the determination and relative contribution of factors resulting in thirst.

453

\section{Conclusion}

In conclusion, sensations of thirst and mouth dryness increased following a period of HIIE and remained until satiated by voluntary fluid intake. Sensations of thirst appeared to be 
457 largely driven by an increase in serum osmolality, caused by an increase in blood lactate and 458 serum sodium concentrations.

459 
References

461 [1] Greenleaf JE. Problem - Thirst, drinking behavior, and involuntary dehydration. Med. Sci. Sports Exerc. 1992;24(6):645-56.

[2] Stricker EM, Verbalis JG. Hormones and behavior - the biology of thirst and sodium appetite. Am. Sci. 1988;76(3):261-7.

465

466

467

468

469

470

471

472

473

474

475

476

477

478

479

480

481

482

483

484

485

[3] Brunstrom JM, Tribbeck PM, MacRae AW. The role of mouth state in the termination of drinking behavior in humans. Physiol. Behav. 2000;68(4);579-83.

[4] Figaro MK, Mack GW. Regulation of fluid intake in dehydrated humans: Role of oropharyngeal stimulation. Am. J. Physiol-Regul. Integr. Comp. Physiol. 1997;272(6):R1740-R1746.

[5] Seckl JR, Williams TDM, Lightman SL. Oral hypertonic saline causes transient fall of vasopressin in humans. Am. J. Physiol. 1986;251(2):R214-R217.

[6] Thompson CJ, Bland J, Burd J, Baylis PH. The osmotic thresholds for thirst and vasopressin release are similar in healthy man. Clin. Sci. 1986;71:651-6.

[7] Phillips PA, Rolls BJ, Ledingham JGG, Forsling ML, Morton JJ. Osmotic thirst and vasopressin release in humans - a double-blind crossover study. Am. J. Physiol. 1985;248:R645-R650.

[8] Cheuvront SN, Kenefick RW. Dehydration: Physiology, Assessment, and Performance Effects. Comp. Physiol, 2014;4(1):257-85.

[9] McKinley MJ, Johnson AK. The physiological regulation of thirst and fluid intake. News Physiol. Sci. 2004;19:1-6.

[10] Mears SA, Shirreffs SM. The effects of high intensity intermittent exercise compared with continuous exercise on voluntary water ingestion. Int. J. Sports Nutr. Exerc. Metab. 2013;23(5):488-97.

[11] Wolf AV. Thirst; physiology of the urge to drink and problems of water lack. Springfield, IL: Charles C Thomas Publisher; 1950. 
[12] Sjøgaard G, Adams RP, Saltin B. Water and ion shifts in skeletal-muscle of humans with intense dynamic knee extension. Am. J. Physiol. 1985;248:R190-R196.

[13] Convertino VA, Keil LC, Bernauer EM, Greenleaf JE. Plasma-volume, osmolality, vasopressin, and renin-activity during graded-exercise in man. J. Appl. Physiol. 1981;50:123-8.

[14] Nose H, Takamata A, Mack GW, Oda Y, Okuno T, Kang DH, Morimoto T. Water and electrolyte balance in the vascular space during graded-exercise in humans. J. Appl. Physiol. 1991;70:2757-62.

[15] Hew-Butler T, Noakes TD, Soldin SJ, Verbalis JG. Acute changes in endocrine and fluid balance markers during high-intensity, steady-state, and prolonged endurance running: unexpected increases in oxytocin and brain natriuretic peptide during exercise. Eur. J. Endocrinol. 2008;159:729-37.

[16] Pilegaard H, Domino K, Noland T, Juel C, Hellsten Y, Halestrap AP, Bangsbo J. Effect of high-intensity exercise training on lactate/H+ transport capacity in human skeletal muscle. Am. J. Physiol-Endocrinol. Metab. 1999;276(2):E255-E261.

[17] Ramanathan NL. New weighting system for mean surface temperature of human body. J. Appl. Physiol. 1964;19:531-3.

[18] Dill DB, Costill DL. Calculation of percentage changes in volumes of blood, plasma, and red-cells in dehydration. J. Appl. Physiol. 1974;37:247-8.

[19] Maughan RJ. A simple, rapid method for the determination of glucose, lactate, pyruvate, alanine, 3-hydroxybutyrate and acetoacetate on a single 20- $\mu$ l blood-sample. Clin. Chim. Acta. 1982;122:231-40.

[20] Armstrong LE, Maresh CM, Castellani JW, Bergeron MF, Kenefick RW, LaGasse KE, Riebe D. Urinary indices of hydration status. Int. J. Sport. Nutr. 1994;4(3):265-79.

[21] Cheuvront SN, Ely BR, Kenefick RW, Sawka MN. Biological variation and diagnostic accuracy of dehydration assessment markers. Am. J. Clin. Nutr. 2010;92:565-73. 
512

513

514

515

516

517

518

519

520

521

522

523

524

525

526

527

528

529

530

531

532

533

534

535

536

537

[22] Guest S, Essick G, Young M, Lee A, Phillips N, McGlone F. Oral hydration, parotid salivation and the perceived pleasantness of small water volumes. Physiol. Behav. 2006;89(5):724-34.

[23] Engell DB, Maller O, Sawka MN, Francesconi RN, Drolet L, Young AJ. Thirst and fluid intake following graded hypohydration levels in humans. Physiol. Behav. 1987;40(2):229-36.

[24] Mack GW, Weseman CA, Langhans GW, Scherzer H, Gillen CM, Nadel ER. Body-fluid balance in dehydrated healthy older men - thirst and renal Osmoregulation. J. Appl. Physiol. 1994;76(4):1615-23.

[25] Sawka MN, Burke LM, Eichner ER, Maughan RJ, Montain SJ, Stachenfeld NS. Exercise and fluid replacement. Med. Sci. Sports Exerc. 2007;39:377-90.

[26] Freund BJ, Claybaugh JR, Dice MS, Hashiro GM. Hormonal and vascular fluid responses to maximal exercise in trained and untrained males. J. Appl. Physiol. 1987;63(2):669-75.

[27] Worthley LI, Guerin M, Pain RW. For calculating osmolality, the simplest formula is the best. Anaesth. Intensive Care 1987;15:199-202.

[28] Wong SH, Williams C, Simpson M, Ogaki T. Influence of fluid intake pattern on shortterm recovery from prolonged, submaximal running and subsequent exercise capacity. J. Sports Sci. 1998;16(2):143-52.

[29] Beis LY, Wright-Whyte M, Fudge B, Noakes T, Pitsiladis YP. Drinking behaviors of elite male runners during marathon competition. Clin. J. Sport Med. 2012;22(3):254-61.

[30] Rolls BJ, Wood RJ, Rolls ET, Lind H, Lind W, Ledingham JGG. Thirst following waterdeprivation in humans. Am. J. Physiol. 1980;239:R476-82. 
539 Table 1. Body mass (BM) and water variables for all trials. $†$ denotes pre to post measurement difference, *

540 denotes different to $\mathrm{W}$ trial, \# denotes different to $\mathrm{W}$ and $\mathrm{W} 30$ trials $(\mathrm{p}<0.05)$. BM = body mass.

\begin{tabular}{cccccccc}
\hline Trial & $\begin{array}{c}\text { Pre BM } \\
(\mathrm{kg})\end{array}$ & $\begin{array}{c}\text { Post BM } \\
(\mathrm{kg})\end{array}$ & $\begin{array}{c}\text { BM change } \\
(\%)\end{array}$ & $\begin{array}{c}\text { Water } \\
\text { intake }(\mathrm{l})\end{array}$ & $\begin{array}{c}\text { Sweat } \\
\text { loss }(\mathrm{l})\end{array}$ & $\begin{array}{c}\text { Urine } \\
\text { Output }(\mathrm{l})\end{array}$ & $\begin{array}{c}\text { Water replaced } \\
(\%)\end{array}$ \\
\hline & 79.9 & 79.7 & -0.25 & 0.85 & 0.83 & 0.21 & 82 \\
$\mathrm{~W}$ & \pm 8.9 & \pm 8.9 & \pm 0.54 & \pm 0.42 & \pm 0.18 & \pm 0.10 & \pm 39 \\
& 79.8 & 79.4 & -0.49 & 0.63 & 0.82 & 0.21 & 63 \\
W30 & \pm 8.9 & $\pm 8.9 \dagger$ & \pm 0.37 & $\pm 0.28^{*}$ & \pm 0.23 & \pm 0.08 & $\pm 27^{*}$ \\
& 80.2 & 79.2 & -1.29 & & 0.84 & 0.21 & - \\
NW & \pm 9.0 & $\pm 9 . \dagger^{*}$ & $\pm 0.37^{\#}$ & - & \pm 0.24 & \pm 0.10 & - \\
\hline
\end{tabular}

541 
542 Table 2. Correlation coefficients (r) and significance levels (p) for measured variables in each trial. (conc. 543 denotes concentration). *denotes significant $(\mathrm{p}<0.05)$. Correlations involving aldosterone are Spearmon’s rank 544 correlations, remaining correlations are Pearson's product moment correlations.

\begin{tabular}{|c|c|c|c|c|c|c|c|}
\hline \multirow[b]{2}{*}{ Variables } & & \multicolumn{2}{|c|}{$\mathbf{W}$} & \multicolumn{2}{|c|}{ W30 } & \multicolumn{2}{|c|}{ NW } \\
\hline & & $\mathbf{r}$ & $\mathbf{p}$ & $\mathbf{r}$ & $\mathbf{p}$ & $\mathbf{r}$ & $\mathbf{p}$ \\
\hline \multirow[t]{6}{*}{ Thirst } & Mouth dryness & 0.959 & $<0.001^{*}$ & 0.921 & $<0.001^{*}$ & 0.775 & $<0.001^{*}$ \\
\hline & Serum osmolality & 0.562 & $<0.001^{*}$ & 0.314 & $0.005^{*}$ & 0.292 & $0.01 *$ \\
\hline & Serum sodium conc. & 0.535 & $<0.001^{*}$ & 0.554 & $<0.001^{*}$ & 0.499 & $<0.001^{*}$ \\
\hline & Blood lactate conc. & 0.494 & $<0.001^{*}$ & 0.528 & $<0.001^{*}$ & 0.421 & $<0.001 *$ \\
\hline & AVP conc. & 0.376 & $0.013 *$ & 0.456 & $0.003^{*}$ & 0.226 & 0.150 \\
\hline & Aldosterone conc. & 0.268 & 0.079 & 0.173 & 0.261 & 0.099 & 0.524 \\
\hline \multirow[t]{5}{*}{ Mouth dryness } & Serum osmolality & 0.567 & $<0.001^{*}$ & 0.406 & $<0.001^{*}$ & 0.119 & 0.301 \\
\hline & Serum sodium conc. & 0.518 & $<0.001^{*}$ & 0.610 & $<0.001^{*}$ & 0.560 & $<0.001^{*}$ \\
\hline & Blood lactate conc. & 0.466 & $<0.001^{*}$ & 0.525 & $<0.001^{*}$ & 0.373 & $0.001^{*}$ \\
\hline & AVP conc. & 0.398 & $0.008^{*}$ & 0.328 & $0.037^{*}$ & 0.115 & 0.469 \\
\hline & Aldosterone conc. & 0.271 & 0.076 & 0.131 & 0.396 & 0.070 & 0.653 \\
\hline Serum & Serum sodium conc. & 0.646 & $<0.001^{*}$ & 0.555 & $<0.001^{*}$ & 0.424 & $<0.001^{*}$ \\
\hline \multirow[t]{3}{*}{ osmolality } & Blood lactate conc. & 0.824 & $<0.001^{*}$ & 0.773 & $<0.001^{*}$ & 0.813 & $<0.001 *$ \\
\hline & AVP conc. & 0.621 & $<0.001^{*}$ & 0.218 & 0.170 & 0.443 & $0.003^{*}$ \\
\hline & Aldosterone conc. & 0.321 & $0.034 *$ & 0.313 & $0.039 *$ & 0.416 & $0.005^{*}$ \\
\hline Serum sodium & Blood lactate conc. & 0.607 & $<0.001^{*}$ & 0.648 & $<0.001^{*}$ & 0.616 & $<0.001^{*}$ \\
\hline \multirow[t]{2}{*}{ conc. } & AVP conc. & 0.501 & $0.001 *$ & 0.218 & 0.171 & 0.183 & 0.247 \\
\hline & Aldosterone conc. & 0.412 & $0.005^{*}$ & 0.194 & 0.206 & 0.197 & 0.200 \\
\hline Blood lactate & AVP conc. & 0.720 & $<0.001^{*}$ & 0.471 & $0.002^{*}$ & 0.470 & $0.002 *$ \\
\hline conc. & Aldosterone conc. & 0.431 & $0.004 *$ & 0.379 & $0.011^{*}$ & 0.446 & $0.002 *$ \\
\hline AVP conc. & Aldosterone conc. & 0.380 & $0.012 *$ & 0.174 & 0.276 & 0.313 & $0.044 *$ \\
\hline
\end{tabular}

